\title{
Domperidone for lactating women
}

Reason for posting: Domperidone has been widely used as a motility and antiemetic agent. ${ }^{1}$ In oral form it is also used off label to improve lactation in breast-feeding women. Intravenous domperidone has been withdrawn from the market worldwide because of reports of cardiac arrhythmia and sudden death in patients with malignant disease who received relatively high intravenous doses of the drug for nausea and vomiting induced by cytotoxic therapy. ${ }^{2-5}$ In the United States, it is not approved for any indication and thus is not marketed in any form. ${ }^{6}$ However, some breastfeeding women in the United States have been purchasing the oral form of the drug from compounding pharmacies and from sources in other countries in order to enhance lactation. The US Food and Drug Administration (FDA) has warned breastfeeding women not to use domperidone because of its potentially adverse effects. ${ }^{6}$ It has also expressed concerns about the unknown but potential risks to the breast-feeding infant since the drug is excreted in breast milk.?

The drug: Dopamine is a physiologic inhibitor of prolactin release from the pituitary gland. Domperidone is a peripheral dopamine-receptor antagonist, which is why its administration increases prolactin concentration and milk production. ${ }^{1,7}$ Domperidone has been approved for oral use in Canada and worldwide as a motility agent with an excellent safety record. ${ }^{1}$ As an antiemetic, the drug is usually given at an oral dose of $60-80 \mathrm{mg} / \mathrm{d}$; as a galactagogue, the current evidence supports a dose of $30 \mathrm{mg} / \mathrm{d}$. $^{7}$ Because of extensive first-pass and gut-wall metabolism, oral bioavailability is only $13 \%-17 \%$. $^{1}$ Heykants and associates $^{8}$ reported peak blood levels of $23 \mathrm{ng} / \mathrm{mL}$ after an oral dose of $10 \mathrm{mg}$ of domperidone, compared with levels about 30 times higher with the same dose given intravenously. In women receiving $10 \mathrm{mg}$ of domperidone 3 times daily to enhance lactation, the mean serum level on day 5 of therapy was $6.6 \mathrm{ng} / \mathrm{mL}$.? With respect to risks to the nursing infants, the mean level of domperidone excreted in the breast milk of women taking $10 \mathrm{mg}$ of domperidone orally 3 times daily was only $1.2 \mathrm{ng} / \mathrm{mL}$. $^{7}$ The total amount of the drug that would be ingested by the infant would be extremely small (about $180 \mathrm{ng} / \mathrm{kg}$ daily, assuming a daily milk intake of $150 \mathrm{~mL} / \mathrm{kg}$ ).

What to do: The data on the use of domperidone orally as a galactagogue are limited. However, FDA warnings against the use of domperidone by lactating women were based on the increased risk of cardiac arrhythmia and sudden death in patients with malignant disease receiving highdose intravenous domperidone therapy concurrently with chemotherapy. All of the patients whose serum potassium level was measured had low levels (between 2.0 and $3.3 \mathrm{mmol} / \mathrm{L}$ ). ${ }^{4.5}$

Breast-feeding is recommended as the optimal form of nutrition for term and preterm infants for the psychological benefits of maternal-infant bonding and the nutritional properties of breast milk. Lactating women with decreased milk supply who are unresponsive to nonpharmacologic measures to enhance lactation, including counselling, relaxation techniques and mechanical expression, should continue to consider domperidone at antiemetic doses. Patients should be warned of the risk of lifethreatening cardiac arrhythmias associated with high doses of domperidone, and women with known cardiac disease should refrain from using the drug. Further research is needed to define the best dose of domperidone and length of treatment in lactating women with reduced milk production.
Orlando P. da Silva
Department of Paediatrics
David C. Knoppert
Department of Pharmacy
University of Western Ontario
St. Joseph's Health Care London
London, Ont.

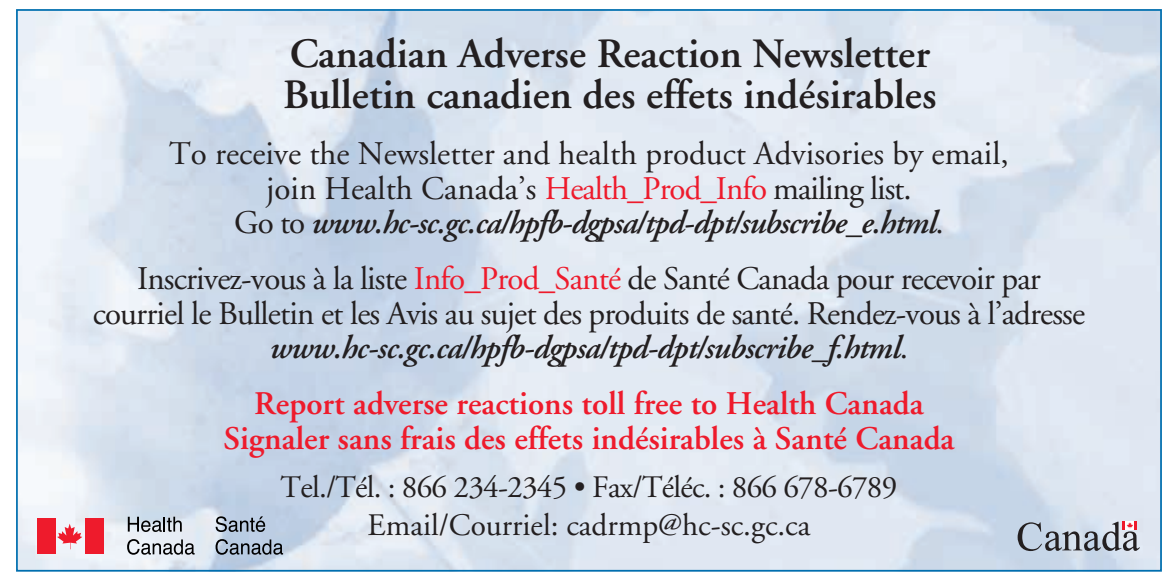


References

1. Barone JA. Domperidone: a peripherally acting dopamine ${ }_{2}$-receptor antagonist. Ann Pharmacother 1999;33: 429-40.

2. Joss RA, Goldhirsch A, Brunner KW, Galeazzi RL. Sudden death in cancer patient on high-dose domperidone. Lancet 1982;1:1019.

3. Giaccone G, Bertetto O, Calciati A. Two deaths during prophylactic antiemetic treatment with high doses of domperidone and methylprednisolone. Lancet 1984;2:1336-7.

4. Osborne RJ, Slevin ML, Hunter RW,
Hamer J. Cardiotoxicity of intravenous domperidone. Lancet 1985;2: 385.

5. Roussak JB, Carey P, Parry H. Cardiac arrest after treatment with intravenous domperidone. BM7 (Clin Res Ed) $1984 ; 289: 1579$

6. US Food and Drug Administration. FDA warns against women using unapproved drug, domperidone, to increase milk production [FDA Talk Paper]. Rockville (Md): FDA; 2004 June 7. Available: www.fda.gov/bbs /topics/ANSWERS/2004/ANS01292 .html (accessed 2004 Aug 31).
7. Da Silva OP, Knoppert DC, Angelini MM, Forret PA. Effect of domperidone on milk production in mothers of premature newborns: a randomized, double-blind, placebo-controlled trial. CMA7 2001;164(1):17-21.

8. Heykants J, Hendriks R, Meuldermans W, Michiels M, Scheygrond H, Reyntjens $\mathrm{H}$. On the pharmacokinetics of domperidone in animals and man. IV. The pharmacokinetics of intravenous domperidone and its bioavailability in man following intramuscular, oral and rectal administration. Eur 7 Drug Metab Pharmacokinet 1981;6(1):61-70.

IN THE LITERATURE

\section{Should people with asymptomatic carotid artery stenosis undergo endarterectomy for primary stroke prevention?}

Halliday A, Mansfield A, Marro J, Peto C, Peto R, Potter J, et al; MRC Asymptomatic Carotid Surgery Trial (ACST) Collaborative Group. Prevention of disabling and fatal strokes by successful carotid endarterectomy in patients without recent neurological symptoms: randomised controlled trial. Lancet 2004;363:1491-502.

Background: Carotid endarterectomy (CE) is well established as a beneficial procedure for reducing the risk of stroke among patients with symptomatic high-grade carotid artery disease. ${ }^{1}$ However, its role in reducing the risk among patients with asymptomatic carotid artery stenosis (i.e., no prior cerebral or retinal transient ischemic attack [TIA] or stroke) has been less certain and the subject of much controversy. ${ }^{2}$

Design: This multicentre randomized trial is the world's largest vascular surgery trial. From 1993 to 2003, it enrolled 3120 asymptomatic patients with carotid artery stenosis $\geq 60 \%$ (on ultrasound). Patients were randomly allocated to either immediate $\mathrm{CE}$ or medical therapy and deferral of $\mathrm{CE}$. Patients with poor surgical risk or a cardiac source of emboli were excluded. Surgeons were re$\vec{\sim}$ quired to have a perioperative risk of stroke or death of $6 \%$ or less. Medical treatment was left to the discretion of the treating physician. The main outcomes were perioperative morbidity and mortality, and the incidence of nonperioperative stroke.
Results: The risk of stroke or death within 30 days of CE was $3.1 \%$. The overall 5 -year risk of stroke (including perioperative stroke) was lower in the immediate surgery group than in the medical therapy group $(6.4 \% \mathrm{v}$. $11.8 \%, p<0.0001$ ), for a relative risk reduction of about $50 \%$. Subgroup analyses showed a statistical benefit in favour of immediate CE for both men and women, but not for patients aged 75 years and older. CE was particularly beneficial in those with elevated cholesterol.

Commentary: Asymptomatic carotid artery stenosis (unlike symptomatic carotid artery stenosis) is a relatively low-risk condition, and this study confirms its natural history. The annual risk of stroke without surgery was about $2 \%$, which is consistent with findings from previous studies; the annual risk of disabling or fatal stroke was only about $1 \%$.

This trial provides evidence that $\mathrm{CE}$ is efficacious for primary stroke prevention, but the absolute benefit is small (annual absolute risk reduction about $1 \%)$. The study's main end point included all stroke types. If one focuses only on prevention of a disabling or fatal carotid territory ischemic stroke (the main indication for $\mathrm{CE}$ ), the absolute benefit derived from surgery is even smaller. For every 100 patients operated on, about 7 carotid territory strokes (but only 3 disabling or fatal carotid territory ischemic strokes) would be prevented at 5 years and 3 additional strokes or deaths would be caused as a perioperative complication. With advances in medical management, including aggressive reduction of risk factors and more widespread use of preventive treatments, the benefit of surgery may be further narrowed.

The patients in this trial faced an extremely low surgical morbidity and mortality that is difficult to achieve outside of a clinical trial. Because complication rates of $\mathrm{CE}$ are inversely proportional to both hospital and surgeon case volumes, the procedure should not be performed in asymptomatic patients in centres with low case volumes or where the perioperative stroke and death rate exceeds $3 \%$. Independent audits of perioperative complication rates should be made readily available to referring physicians and patients contemplating this procedure. Furthermore, caution is urged when surgical decisions are based solely on carotid ultrasonography, which may misclas- 